\title{
Effects of Hydrogen Diffusion on the Mechanical Properties of Austenite 316L Steel at Ambient Temperature
}

\author{
Yunsung $\mathrm{Kim}^{1, * 1}$, Youngsuk $\mathrm{Kim}^{2}$, Daewhan $\mathrm{Kim}^{2}$, \\ Sungsoo Kim ${ }^{2}$, Wonjong Nam ${ }^{1}$ and Heeman Choe ${ }^{1, * 2}$ \\ ${ }^{1}$ School of Advanced Materials Engineering, Kookmin University, Jeongneung-dong, Seongbuk-gu, Seoul, 136-702, Korea \\ ${ }^{2}$ Zirconium Team, Korea Atomic Energy Research Institute, 150-1 Dukjin-dong, Yuseong-ku, Daejeon, 305-353, Korea
}

\begin{abstract}
This study examined how the strain rate affects the room-temperature tensile behavior of hydrogen-charged 316L stainless steels. A hightemperature homogenization treatment was applied to the specimens after hydrogen charging and copper electroplating to remove the hydrogen concentration gradient. A softening phenomenon was observed in the hardening behavior of the $\mathrm{H}$-charged and homogenized specimen at a strain rate of $2 \times 10^{-3} / \mathrm{s}$. The observation was further confirmed by an inspection of the fracture surface of the tensile test specimen. [doi:10.2320/matertrans.M2010273]
\end{abstract}

(Received August 12, 2010; Accepted December 2, 2010; Published February 25, 2011)

Keywords: hydrogen embrittlement, steel, ductility, electrochemical charging, mechanical properties

\section{Introduction}

Over the past few decades, the interaction between hydrogen and metals has been studied extensively in many areas for a number of reasons, e.g. to develop solid hydrogen storage systems for transportation applications, ${ }^{1)}$ to observe the transformation superplastic (TSP) deformation or internal-stress plasticity (ISP) caused by repetitive hydrogen cycling, ${ }^{2-4)}$ and to resolve the concerns regarding hydrogen embrittlement (HE) phenomenon, which can degrade significantly the mechanical properties of metallic materials. With HE, metals can fail at very low load levels with reduced ductility compared to those that a hydrogen-free material can sustain normally. ${ }^{5-7)}$

As such, the HE phenomenon in steels is an important subject and has been examined by a number of researchers for advanced structural applications, such as nuclear power plants and gas/oil industry where there are several hydrogen sources. ${ }^{8-12)}$ In particular, 316L austenite stainless steels are becoming increasingly popular as advanced structural materials in light water reactors (LWRs) or liquid metal reactors (LMRs) in nuclear power plants owing to their combination of strength and ductility, fracture toughness, corrosion resistance as well as low absorption rate of neutron radiation. ${ }^{13-15)}$

For the HE study, the interaction between hydrogen and steels is generally induced either by cathodic or gas-phase charging. In general, cathodic charging is easier to perform but gas-phase charging can achieve a more uniform hydrogen distribution, as the relatively small diffusion distances obtained during a laboratory-scale cathodic charging process leave the hydrogen transport limited to near the surface. ${ }^{16,17)}$ Alternatively, the cathodic charging process could be attempted on steel samples in the form of foils ${ }^{18,19)}$ or flat rectangular shape ${ }^{20)}$ to ensure more uniform hydrogen distribution throughout the sample thickness. In this study,

\footnotetext{
${ }^{* 1}$ Graduate Student, Kookmin University

${ }^{* 2}$ Corresponding author, E-mail: heeman@kookmin.ac.kr
}

the forced charging of hydrogen was achieved also using a cathodic charging technique to simulate the mechanistic role of hydrogen in 316L austenite stainless steels. Furthermore, unlike previous studies, ${ }^{8,10,12,21,22)}$ the $\mathrm{H}$ charging process was followed by a high-temperature heat-treatment to remove the initially inhomogeneous hydrogen concentration gradient that usually occurs after cathodic charging. ${ }^{12,21,23)}$ The room-temperature tensile properties of the $316 \mathrm{~L}$ austenite stainless steel with and without the homogenization process were examined and compared at different strain rates. In particular, this paper concerns an effect of a small amount of uniformly distributed hydrogen (in the range of several ppm (parts per million) hydrogen by weight) on the roomtemperature tensile properties of 316L stainless steel. A small amount and yet uniform distribution of hydrogen content appeared to result in softening of the $316 \mathrm{~L}$ austenitic stainless steel with reductions in both room-temperature strength and ductility, as previously reported elsewhere. ${ }^{17,24)}$

\section{Experimental Procedures}

316L austenite stainless steel was prepared by a homogenization process at $1100^{\circ} \mathrm{C}$, followed by quenching in water. Its chemical composition is listed in Table 1. A cathodic hydrogen charging technique was employed at $94 \sim 98^{\circ} \mathrm{C}$ for $\sim 50$ min using a $0.5 \mathrm{M} \mathrm{H}_{2} \mathrm{SO}_{4}$ solution with $250 \mathrm{mg} / \mathrm{L} \mathrm{As}_{2} \mathrm{O}_{3}$ as the hydrogen recombination poison. A current density of $200 \mathrm{~A} / \mathrm{m}^{2}$ was applied between the $316 \mathrm{~L}$ stainless steel sample and a platinum anode. The details of hydrogen charging process used in this study are compared with those of other studies in Table 2. After the hydrogen charging process, the samples were then electroplated with copper to prevent hydrogen desorption because the diffusivity of hydrogen in copper is much lower than that in $316 \mathrm{~L}$ austenite steel. ${ }^{25}$ ) One liter of electroplating solution contained $22.5 \mathrm{~g}$ cuprous cyanide, $33.7 \mathrm{~g}$ sodium cyanide, $15.0 \mathrm{~g}$ sodium carbonate, and $0.2 \mathrm{~g}$ sodium thiosulfate, with the $\mathrm{pH}$ maintained at $12.0 \sim 12.5$. The electroplating process was conducted for $\sim 5$ min at $1-2 \mathrm{~V}$ and at $33-39^{\circ} \mathrm{C}^{10)}$ Several tensile 
Table 1 Chemical composition of the 316L stainless steel used in this study.

\begin{tabular}{cccccccccccccc}
\hline Comp. & $\mathrm{Fe}$ & $\mathrm{C}$ & $\mathrm{Si}$ & $\mathrm{Mn}$ & $\mathrm{P}$ & $\mathrm{S}$ & $\mathrm{Cr}$ & $\mathrm{Ni}$ & $\mathrm{Mo}$ & $\mathrm{N}$ & $\mathrm{Co}$ & $\mathrm{Cu}$ \\
\hline Mass$\%$ & $\mathrm{Bal}$ & 0.017 & 0.57 & 1.06 & 0.027 & 0.001 & 16.71 & 10.17 & 2.02 & 0.031 & 0.15 & 0.45 \\
\hline
\end{tabular}

Table 2 Description of the hydrogen charging process compared with other studies.

\begin{tabular}{|c|c|c|c|c|c|c|}
\hline References & Present study & Ref. 8) & Ref. 10) & Ref. 11) & Ref. 21) & Ref. 22) \\
\hline \multirow[t]{3}{*}{ Charging solution } & $1 \mathrm{M} \mathrm{H}_{2} \mathrm{SO}_{4}$ & $1 \mathrm{M} \mathrm{H}_{2} \mathrm{SO}_{4}$ & $0.5 \mathrm{M} \mathrm{H}_{2} \mathrm{SO}_{4}$ & $0.1 \mathrm{M} \mathrm{NaOH}$ & $1 \mathrm{M} \mathrm{H}_{2} \mathrm{SO}_{4}$ & $0.5 \mathrm{M} \mathrm{H}_{2} \mathrm{SO}_{4}$ \\
\hline & $+250 \mathrm{mg} / \mathrm{L}$ & $+250 \mathrm{mg} / \mathrm{L}$ & $+250 \mathrm{mg} / \mathrm{L}$ & $+0.5 \mathrm{M}$ & $+250 \mathrm{mg} / \mathrm{L}$ & $+250 \mathrm{mg} / \mathrm{L}$ \\
\hline & $\mathrm{As}_{2} \mathrm{O}_{3}$ & $\mathrm{As}_{2} \mathrm{O}_{3}$ & $\mathrm{As}_{2} \mathrm{O}_{3}$ & $\mathrm{H}_{2} \mathrm{SO}_{4}$ & $\mathrm{As}_{2} \mathrm{O}_{3}$ & $\mathrm{As}_{2} \mathrm{O}_{3}$ \\
\hline \multirow[t]{2}{*}{ Sample } & $316 \mathrm{~L}$ steel & ASTM & ASTM & 316L steel & 316L steel & $308,347 \mathrm{~L}$, \\
\hline & & A508 Cl.3 & A508 Cl.3 & & & 304L steel \\
\hline Current density & $200 \mathrm{~A} / \mathrm{m}^{2}$ & $100 \mathrm{~A} / \mathrm{m}^{2}$ & $100 \mathrm{~A} / \mathrm{m}^{2}$ & $500 \mathrm{~A} / \mathrm{m}^{2}$ & $1000 \mathrm{~A} / \mathrm{m}^{2}$ & $5000 \mathrm{~A} / \mathrm{m}^{2}$ \\
\hline Anode material & $\mathrm{Pt}$ & $\mathrm{Pt}$ & $\mathrm{Pt}$ & - & $\mathrm{Pt}$ & - \\
\hline Charging time & $50 \mathrm{~min}$ & $30 \mathrm{~min}$ & $30 \mathrm{~min}$ & $72 \mathrm{~h}$ & $24 \mathrm{~h}$ & $48 \mathrm{~h}$ \\
\hline Homogenization & $600^{\circ} \mathrm{C}$ at & No & No & No & No & No \\
\hline after $\mathrm{H}$ charging & $2 \mathrm{~h}$ & & & & & \\
\hline
\end{tabular}

samples were homogenized at $600^{\circ} \mathrm{C}$ for $2 \mathrm{~h}$ to remove the hydrogen concentration gradient throughout their thickness dimension. The outer surface of a homogenized specimen had been ground off by approximately $1.0 \mathrm{~mm}$ before its hydrogen concentration was measured and compared to that of an as-homogenized specimen. Hydrogen concentration measurements were performed using a LECO RH 404 analyzer ${ }^{26)}$ In addition, the hydrogen contents were determined by averaging three different test values for each specimen.

The microstructure of cross sections of specimens was examined by optical microscopy. The cross sections were produced by normal metallographic sample preparation techniques. For the metallographic examination, the sample was etched with aqua regia for $3 \mathrm{~min}$. The macro-hardness was measured using a standard B-scale Rockwell hardness tester with a $1.6 \mathrm{~mm}$ diameter steel ball, a $10 \mathrm{~kg}$ minor load, and a $100 \mathrm{~kg}$ major load on epoxy-mounted specimens that had been ground and polished to $0.3 \mu \mathrm{m}$ with colloidal alumina. For comparison, micro-hardness measurements were also performed particularly on the inner regions of the homogenized specimens with and without hydrogen, using a Vickers indenter with a $100 \mathrm{~g}$ load and an indent time of $10 \mathrm{~s}$ on epoxy-mounted cross-sections of the samples.

A room-temperature tensile test was performed on the samples that had been machined to the ASTM E-8 proportional standards. ${ }^{27)}$ Cylindrical specimens were machined with a gauge length and diameter of $30.0 \mathrm{~mm}$ and $3.8 \mathrm{~mm}$, respectively. The cross-head speed varied from 0.36 to $17.82 \mathrm{~mm} / \mathrm{min}$, corresponding to strain rates of $2 \times 10^{-4}$ to $1 \times 10^{-2} / \mathrm{s}$. The strain was measured using a clip-on extensometer with a $25.0 \mathrm{~mm}$ gauge length. The fracture surfaces of several samples after the tensile test were examined by scanning electron microscopy (SEM).

\section{Results and Discussion}

\subsection{Microstructure and hardness}

Figure 1(a) presents an optical micrograph of the etched cross-section of a $316 \mathrm{~L}$ austenite steel specimen charged with (a)

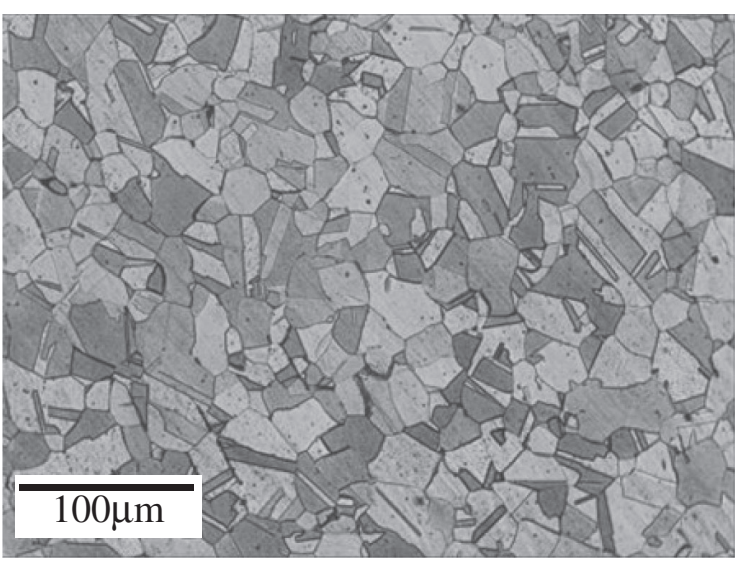

(b)

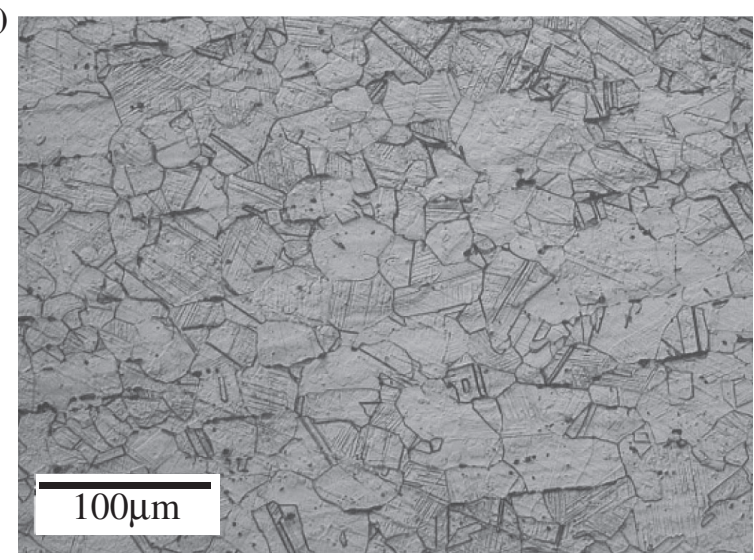

Fig. 1 Optical micrographs of 316L stainless steel used in this study: (a) a sample charged with $\mathrm{H}$ but not homogenized and (b) a sample charged with $\mathrm{H}$ and homogenized.

hydrogen, showing the typical characteristics of austenite stainless steel with an average grain size of $\sim 31 \pm 8 \mu \mathrm{m}$. Some samples were homogenized at $600^{\circ} \mathrm{C}$ for $2 \mathrm{~h}$ for a uniform hydrogen distribution and there was essentially no or little difference detected in their microstructure with the similar average grain size of $\sim 35 \pm 14 \mu \mathrm{m}$, except for a more amount of twins observed and possible presence of chromium 
Table 3 Tensile properties and hardness of $316 \mathrm{~L}$ stainless steels tested in the present study.

\begin{tabular}{|c|c|c|c|c|c|}
\hline Specimen type & $\begin{array}{c}\text { Rockwell Hardness, } \\
H R B / \mathrm{HRB}\end{array}$ & $\begin{array}{c}\text { Strain Rate, } \\
\dot{\varepsilon} / \mathrm{s}\end{array}$ & $\begin{array}{c}0.2 \% \text { Yield Strength, } \\
\sigma / \mathrm{MPa}\end{array}$ & $\begin{array}{l}\text { Ultimate Tensile Strength, } \\
\sigma / \mathrm{MPa}\end{array}$ & $\begin{array}{c}\text { Strain to Failure } \\
\qquad(\%)\end{array}$ \\
\hline Not homogenized & \multirow{3}{*}{$68.5 \pm 1.19$} & $1 \times 10^{-2}$ & 283.0 & 653.6 & 58.3 \\
\hline \multirow[t]{2}{*}{ (With H) } & & $2 \times 10^{-3}$ & 267.1 & 662.1 & 63.7 \\
\hline & & $2 \times 10^{-4}$ & 264.4 & 667.3 & 61.6 \\
\hline \multirow{2}{*}{$\begin{array}{l}\text { Not homogenized } \\
\text { (Without } \mathrm{H} \text { ) }\end{array}$} & \multirow[b]{2}{*}{$73.5 \pm 2.76$} & $1 \times 10^{-2}$ & 284.8 & 651.8 & 56.4 \\
\hline & & $2 \times 10^{-3}$ & 270.5 & 677.4 & 72.0 \\
\hline \multirow{3}{*}{$\begin{array}{c}\text { Homogenized } \\
\text { (With } \mathrm{H})\end{array}$} & \multirow{3}{*}{$80.9 \pm 0.45$} & $1 \times 10^{-2}$ & 275.7 & 660.3 & 62.6 \\
\hline & & $2 \times 10^{-3}$ & 256.0 & 660.5 & 58.2 \\
\hline & & $2 \times 10^{-4}$ & 251.4 & 664.2 & 68.0 \\
\hline \multirow{3}{*}{$\begin{array}{l}\text { Homogenized } \\
\text { (Without } \mathrm{H} \text { ) }\end{array}$} & \multirow{3}{*}{$94.4 \pm 1.29$} & $1 \times 10^{-2}$ & 276.8 & 660.4 & 62.7 \\
\hline & & $2 \times 10^{-3}$ & 269.6 & 674.4 & 72.4 \\
\hline & & $2 \times 10^{-4}$ & 258.8 & 667.5 & 73.9 \\
\hline
\end{tabular}

carbide precipitates along the grain boundaries (Fig. 1(b)). The increased hardness for the homogenized specimen without $\mathrm{H}$-charging than for the as-received specimen may be attributed to the presence of chromium carbide precipitates during the heat-treatment (Table 3). For 316L austenitic stainless steel used in this study, the amount of chromium carbide precipitates formed along the grain boundaries is expected to be insignificant due to a much reduced content of carbon ( 0.017 mass $\%)$, as opposed to type 302 alloy (0.1 mass\% C) or type 304 alloy (0.06 mass\%) in which a considerable amount of chromium carbides can precipitate in the grain boundaries in the temperature range of 400 to $850^{\circ} \mathrm{C}$, generally causing them to be susceptible to 'sensitization'. ${ }^{28)}$ The homogenization time used for hydrogen diffusion was based on calculations of the diffusion distance of hydrogen in austenite stainless steel using a representative equation of diffusion distance, $d=\sqrt{2 D t}$. Given the following diffusion coefficient equation (eq. (1)) proposed for the diffusion of hydrogen in $316 \mathrm{~L}$ stainless steel over the temperature range of $23-960^{\circ} \mathrm{C}$ in Ref. 11), the calculated diffusion coefficient $D$ at $94^{\circ} \mathrm{C}$ was $1.4 \times$ $10^{-14} \mathrm{~m}^{2} \mathrm{~s}^{-1}$ and the estimated diffusion depth of hydrogen during the hydrogen charging process was only $0.001 \mathrm{~mm}$

$$
D=\left(6.2 \times 10^{-7}\right)^{*} \exp (-53,630 / R T)
$$

where $D$ is the diffusion coefficient $\left(\mathrm{m}^{2} \mathrm{~s}^{-1}\right), R$ is the gas constant $\left(\mathrm{JK}^{-1} \mathrm{~mol}^{-1}\right)$, and $T$ is temperature in $\mathrm{K}$. The result suggests that charged hydrogen was concentrated near the outer surface of a $316 \mathrm{~L}$ stainless steel sample using the cathodic charging method, as reported previously. ${ }^{11,21,23)}$ On the other hand, the estimate of hydrogen diffusion distance in a $316 \mathrm{~L}$ stainless steel sample after the homogenization treatment at $600^{\circ} \mathrm{C}$ for $2 \mathrm{~h}$ was $2.3 \mathrm{~mm}$ using the same equations, which is large enough taking into account the radius of the tensile samples used in this study $(1.85 \mathrm{~mm})$. The experimentally measured hydrogen content was $5.5 \pm$ $0.3 \mathrm{ppm}$ for the homogenized specimen with the surface ground off by $1.0 \mathrm{~mm}$, which was similar to that for an ashomogenized specimen $(4.3 \pm 0.4 \mathrm{ppm})$, implying that the hydrogen transport was also pertinent to the inner region of the sample. While the homogenization heat-treatment was able to achieve the uniform hydrogen distribution, some degree of hydrogen desorption might have occurred during the process, considering the relatively lower hydrogen contents and decrease in hydrogen concentration after surface removal, as compared to those ranging from several to a few hundred ppm reported in other studies. ${ }^{8,22)}$ Considering the usual residual hydrogen concentration of $1.7 \sim 1.8 \mathrm{ppm}$ in an as-received $316 \mathrm{~L}$ austenitic stainless steel ${ }^{17)}$ and assuming the similar range of hydrogen concentration in our asreceived sample, the hydrogen concentration in our $\mathrm{H}$ charged and homogenized specimen is approximately only three times the residual hydrogen concentration at the highest. Therefore, our discussion is confined to the effect of a 'small' amount of 'internal' hydrogen on austenitic 316L stainless steel.

The Rockwell hardness test performed on the 316L stainless steel samples showed an increase in hardness after the homogenization process at $600^{\circ} \mathrm{C}$ for $2 \mathrm{~h}$ regardless of the presence of hydrogen, as shown in Table 3. Interestingly, the presence of hydrogen appeared to cause softening of the H-charged and homogenized specimen. The hardness of the specimen charged with hydrogen and then homogenized $(81 \pm 0.5 \mathrm{HRB})$ was lower than that of the specimen homogenized but not charged with hydrogen $(94 \pm 1.3$ HRB). In particular, the hardness in the central region of the specimen charged with hydrogen and then homogenized was compared to that of the specimen homogenized but not charged with hydrogen using Vickers hardness method as well (Fig. 2). Similar to a trend observed in the Rockwell hardness result, the average Vickers hardness value of the $\mathrm{H}$ charged and homogenized specimen $(183 \pm 38 \mathrm{HV})$ was also lower than that of the specimen homogenized but uncharged with $\mathrm{H}(230 \pm 31 \mathrm{HV})$, taken only in their central regions. Despite the comparatively smaller differences in yield and tensile strengths, this trend is consistent with the yield and tensile strength behaviors of the two samples, where the yield and tensile strengths of the H-charged and homogenized specimen were slightly lower than those of the specimen homogenized but uncharged with hydrogen as discussed in the following section.

\subsection{Tensile properties and hydrogen effects}

Figure 3 shows representative tensile stress-strain curves 


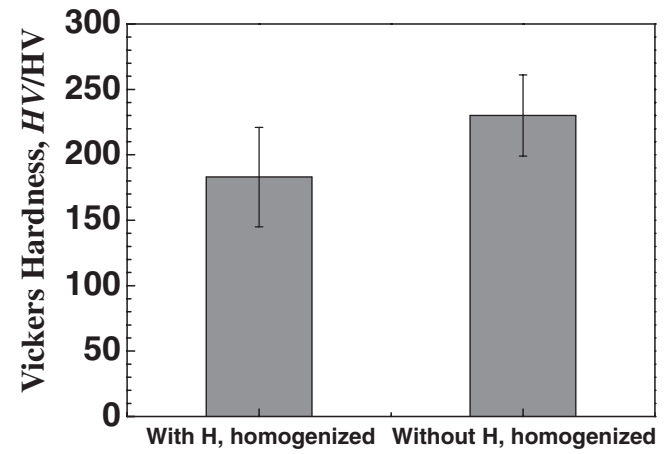

Fig. 2 Comparison of Vickers hardness values of homogenized specimens with and without hydrogen. The hardness measurements were taken only in the central regions of the specimens.

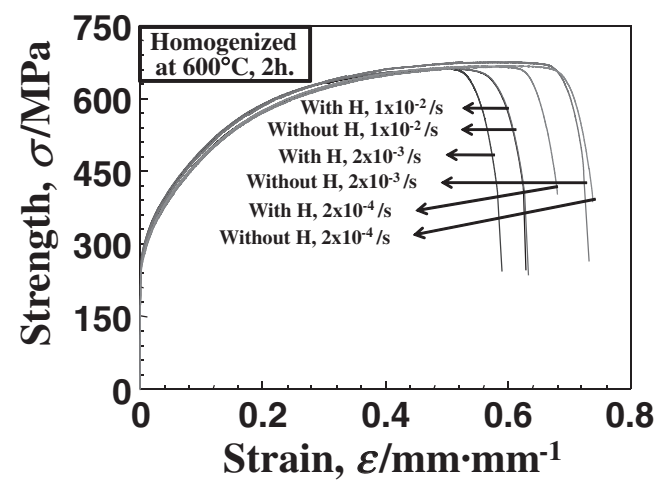

Fig. 3 Tensile stress-strain curves of $316 \mathrm{~L}$ stainless steels with and without hydrogen charging at a strain rate ranging from $2 \times 10^{-4}$ to $1 \times 10^{-2} / \mathrm{s}$.

for the homogenized $316 \mathrm{~L}$ austenite stainless steel samples with and without hydrogen charging at strain rates of $2 \times 10^{-4} / \mathrm{s}, \quad 2 \times 10^{-3} / \mathrm{s}$, and $1 \times 10^{-2} / \mathrm{s}$. Figure 4 and Table 3 show the corresponding mechanical properties. Several points are noteworthy. First, the yield strength increased with increasing strain rate for all samples (Fig. 4(a)), as is generally expected for metallic materials. ${ }^{29)}$ Second, despite small variations of the yield strength by up to $\sim 5 \%$ at most, there was softening or a decreasing trend in both the yield and tensile strengths for the H-charged samples, as compared to the uncharged samples, at strain rates between $2 \times 10^{-4}$ and $2 \times 10^{-3} / \mathrm{s}$. Small variations of the yield strength by hydrogen in austenitic stainless steels are reported to be common, ${ }^{30,31)}$ as they are known to be less susceptible to hydrogen embrittlement, compared to other metals and alloys. ${ }^{17)}$ On the other hand, at a strain rate of $1 \times 10^{-2} / \mathrm{s}$, there was essentially no difference in the yield and tensile strengths between the H-charged and uncharged samples, presumably because at low temperatures and high strain rates, the velocity of hydrogen is too slow to follow that of the dislocation and cause a substantial strain aging effect. ${ }^{32)}$ Furthermore, an evident effect of strain hardening was observed in the homogenized samples at a strain rate of $1 \times 10^{-2} / \mathrm{s}$, because their yield strengths were lower but their tensile strengths were higher than those of the non-homogenized samples. Third, the most pronounced softening effect was observed at a strain rate of $2 \times 10^{-3} / \mathrm{s}$, particularly between the $\mathrm{H}$-charged and uncharged specimens both under (a)

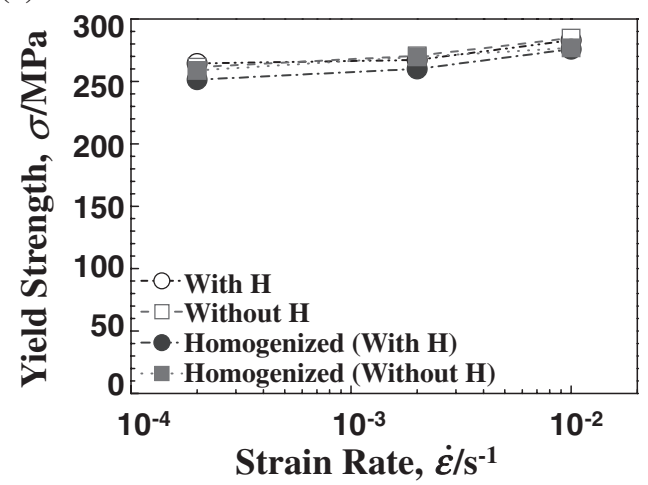

(b)

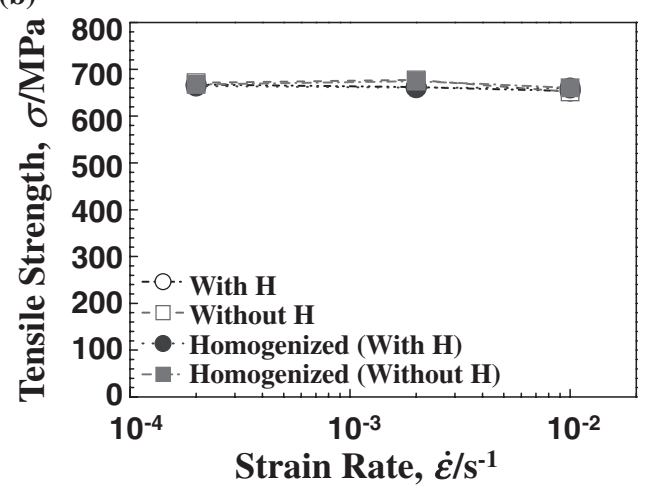

(c)

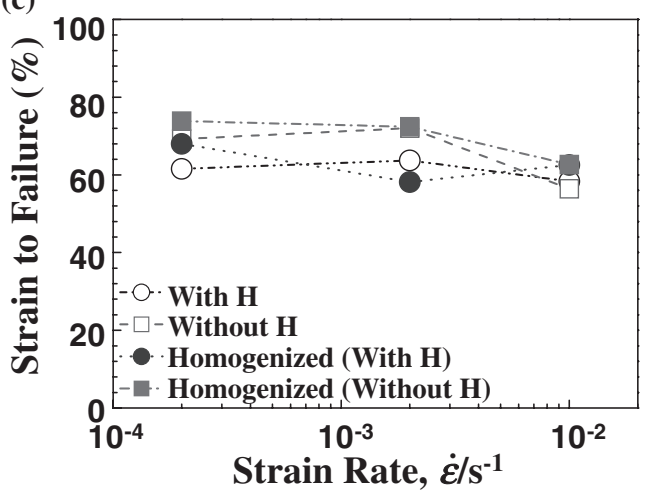

Fig. 4 Dependence of the tensile properties of 316L stainless steels on the strain rate at ambient temperature: (a) yield strength, (b) ultimate tensile strength, and (c) strain to failure.

a homogenization treatment. Indeed, the yield and tensile strengths, and the strain-to-failure of the charged and homogenized specimen were lower than those of the just homogenized specimen; in particular, the strain-to-failure of the former was $72.4 \%$ whereas that of the latter was only $58.2 \%$. This is in good agreement with the literature data in which without exception, the presence of hydrogen always accompanied a reduction of ductility, despite the contradictory effects of hydrogen on yield and tensile strengths of steels. $^{20,33)}$

The disappearance of the hydrogen effect at a strain rate $1 \times 10^{-2} / \mathrm{s}$ may be explained by the interaction of hydrogen with dislocation motion, which can be described by the following equation:

$$
\dot{\varepsilon}_{\mathrm{c}}=\left(\rho_{\mathrm{m}} E_{\mathrm{b}} D_{\mathrm{oH}} / 30 k T\right)^{*} \exp \left(-Q_{\mathrm{H}} / R T\right)
$$


(a)

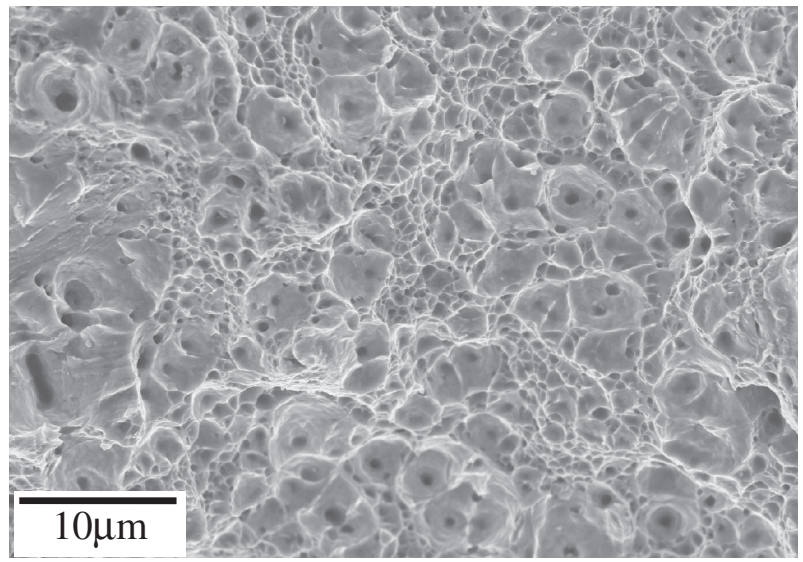

(c)

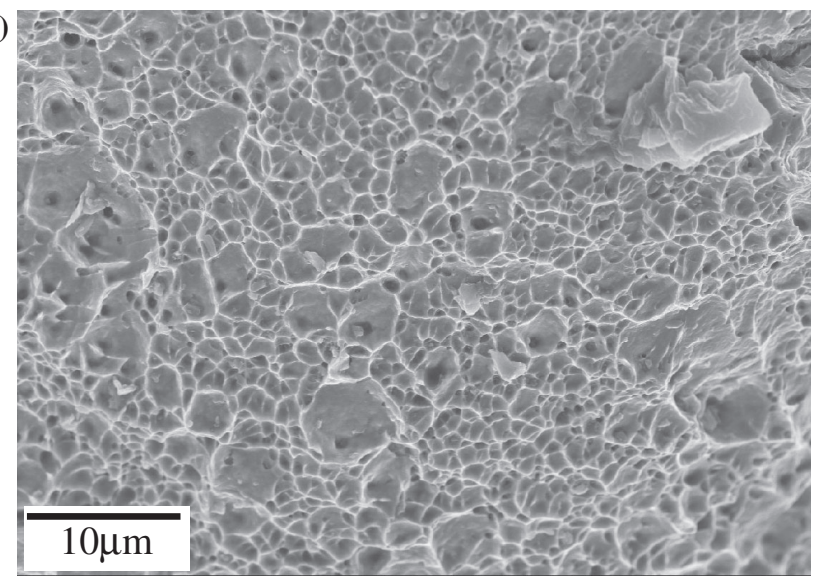

(b)

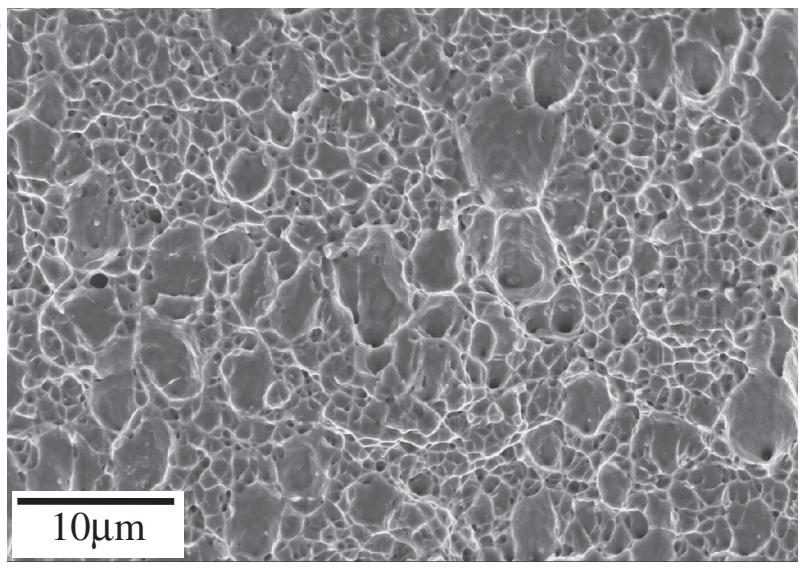

(d)

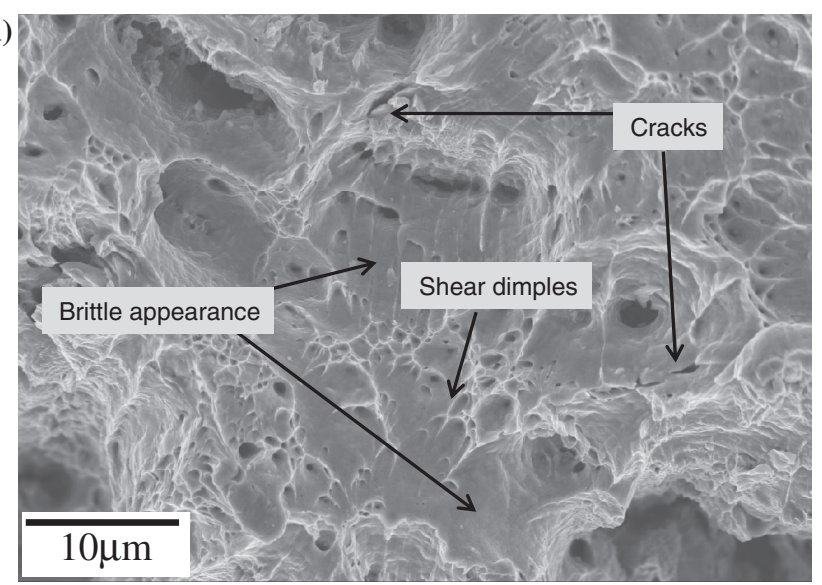

Fig. 5 SEM images of the tensile fracture surfaces of 316L stainless steels: (a) neither charged with H nor homogenized, (b) charged with $\mathrm{H}$ but not homogenized, (c) uncharged with $\mathrm{H}$ but homogenized, and (d) charged with $\mathrm{H}$ and homogenized. Indicated by the arrows are the special features observed in $(\mathrm{d})$.

where $\rho_{\mathrm{m}}$ is the mobile dislocation density, $E_{\mathrm{b}}$ is the binding energy of hydrogen to a moving dislocation, $D_{0 \mathrm{H}}$ is the diffusion constant, $k$ is the Boltzmann constant, $T$ is the absolute temperature, and $Q_{\mathrm{H}}$ is the activation energy of hydrogen. ${ }^{10)}$ In this equation, the effect of hydrogen is associated with a critical strain rate, below which hydrogen movement can follow the dislocation motion to show a considerable effect of hydrogen dissolution. ${ }^{10}$ ) Therefore, Fig. 4 suggests that the critical strain rate, above which the diffusion of hydrogen can no longer follow the dislocation motion, appears to be near $1 \times 10^{-2} / \mathrm{s}$. This critical strain rate is similar to that of $\mathrm{SA} 508 \mathrm{C} 1.3$ steel at $288^{\circ} \mathrm{C}$, as reported in Ref. 10).

On the other hand, the tensile tests at lower strain rates, ranging from $2 \times 10^{-4}$ to $2 \times 10^{-3} / \mathrm{s}$, showed that the mechanical properties of hydrogen-induced samples were slightly degraded compared to the uncharged ones, the difference being more pronounced for the homogenized samples. As a matter of fact, the H-induced softening of the tensile properties in the homogenized specimens was most pronounced at the strain rate of $2 \times 10^{-3} / \mathrm{s}$, as was also reported for SA508 C1.3 steel in Ref. 10). The H-charged sample showed a tensile strength of $660.5 \mathrm{MPa}$, which is lower than that of the uncharged sample $(674.4 \mathrm{MPa})$, and a strain-to-failure of $58.2 \%$, which is reduced by $\sim 20 \%$ as compared to that of the uncharged one $(72.4 \%)$, as shown in Figs. 4(b)-(c).
Figure 5 shows SEM images of the corresponding fracture surfaces in the central regions of the tested tensile specimens at the strain rate of $2 \times 10^{-3} / \mathrm{s}$, which further supports the $\mathrm{H}$-induced softening phenomenon in the $\mathrm{H}$ charged and homogenized specimen. The typical ductile fracture behavior was illustrated predominantly by microvoid coalescence in all four types of samples as shown in Figs. 5(a)-(d). On the other hand, a relatively uniform distribution of fine dimples was observed in Figs. 5(a)-(c), whereas the fracture surface in the $\mathrm{H}$-charged and homogenized sample displayed isolated areas of dimples with a wide range of dimple sizes and a slightly brittle and transgranular appearance. ${ }^{16,19)}$ In particular, the large dimples shown in Fig. 5(d) appeared to be elongated and differ in orientation with a somewhat corrugated appearance, implying that the primary dimple formation process could be the local shear fracture enhanced by hydrogen. ${ }^{16,17)}$ Interestingly, despite the charging of hydrogen, the overall fracture behavior observed in the $\mathrm{H}$-charged specimen without the homogenization process shown in Fig. 5(b) is similar to that of the uncharged, non-homogenized one in Fig. 5(a), which is indicative of the little or no evidence of hydrogen diffusion to the central region of the tensile sample. This suggests that without the homogenization treatment, the interaction of dissolved hydrogen with the cylindrical 316L stainless steel sample used in this study should be confined within its outer region. 
The effect of hydrogen on the softening of the tensile properties or the degraded ductility at $2 \times 10^{-3} / \mathrm{s}$ may be accounted for by a HELP (Hydrogen Enhanced Localized Plasticity) or HID (Hydrogen Induced Decohesion) mechanism for non-hydride forming systems. ${ }^{7)}$ In the HELP mechanism, the dissolved hydrogen actually assists the local plastic deformation in association with dynamic strain aging (DSA) by promoting dislocation multiplication and motion in the Lüders bands, which eventually causes the premature initiation and growth of microvoids within the local regions. This reduces the strength and ductility (softened tensile properties). ${ }^{7,10,34)}$ On the other hand, in the HID mechanism, solute hydrogen is assumed to decrease the force needed to separate the crystallographic plane, grain boundary or a particle/matrix interface by lowering the energy to form a cleaved surface. ${ }^{7)}$ While the interaction of hydrogen with metals and alloys is a rather complex phenomenon and no single mechanism can provide a complete explanation, ${ }^{7)}$ the HELP model is generally used to explain the HE phenomenon (in particular, reduction in ductility) in austenitic steels where hydrogen enhances dislocation mobility but suppresses its cross-slip, resulting in a macroscopically reduced ductility and a brittle fracture appearance, as evidenced in Fig. 5(d). ${ }^{16,17,19,35,36)}$ In our study, despite being disputable without a statistical analysis, both yield and tensile strengths of the H-charged and homogenized specimen appeared to be slightly lower than those of the uncharged but homogenized specimen. Furthermore, the same trend was observed more apparently with Rockwell and Vickers hardness measurements. It is therefore believed that hydrogen softening could occur even with a small amount (several ppm levels) of internal hydrogen when it was evenly distributed, though there have been fewer reports on hydrogen softening ${ }^{17,24,37)}$ than hardening ${ }^{38-41)}$ in the literature. ${ }^{42)}$ In any event, it is difficult to understand their fundamental mechanisms and make direct comparison between them, because there has been a variety of sample geometries and testing conditions used in different studies. While Oguri et al. observed hydrogen softening with particularly low carbon concentrations accompanied, ${ }^{37)}$ other instances of hydrogen softening appear to be associated with internal distribution of hydrogen without a significant hydrogen concentration gradient and consequently high stresses near the surface. ${ }^{42)}$ As a result, without avoiding the abovementioned experimental artifact, the experimental methods used to demonstrate hydrogeninduced hardening have often been subject to criticism. ${ }^{18)}$

Another factor that must be considered for discussing the HE phenomenon in steels is strain-induced martensitic formation during the tensile test, as it is generally known to influence the tensile fracture behavior of type 316 stainless steels at ambient temperature. ${ }^{43)}$ This is because the martensite itself is a brittle phase and the hydrogen diffusivity in the body-centered cubic (bcc) martensite is significantly greater than that in the face-centered cubic (fcc) austenite, giving rise to a more rapid pathway for hydrogen transport in the bcc martensite. ${ }^{16)}$ While very stable austenite stainless steels, such as 310 types and $22 \mathrm{Cr}-13 \mathrm{Ni}-5 \mathrm{Mn}$, are reported to form no strain-induced martensite, its formation can take place in 316 stainless steels with nickel content as high as 13.5 mass \% ${ }^{16,35)}$ Considering the lower nickel content of
10.2 mass $\%$ in the 316L stainless steel used for this study, strain-induced martensite was likely to form during the tensile test, which appeared to help exacerbate the tensile properties of the $\mathrm{H}$-charged and homogenized $316 \mathrm{~L}$ specimen. A quantitative analysis study is further needed for the conclusive experimental evidence of strain-induced martensite in order to determine its exact role on the tensile properties of the H-charged and homogenized specimen.

\section{Conclusions}

This study examined the effect of dissolved hydrogen in 316L stainless steel after achieving a small amount and yet uniform distribution of hydrogen through a homogenization heat-treatment. The room-temperature mechanical properties of the H-charged $316 \mathrm{~L}$ stainless steel were studied at different strain rates. The yield strength increased with increasing strain rate as expected and tended to decrease with $\mathrm{H}$-charging. The tensile strength and ductility however varied in a rather complex manner, depending on the strain rate and whether H-charging and heat-treatment had occurred. The effect of hydrogen seemed to disappear near a strain rate of $1 \times 10^{-2} / \mathrm{s}$, where there were essentially no differences in the yield and tensile strengths, and the ductility between the $\mathrm{H}$-charged and uncharged specimens. The effect of hydrogen was more pronounced in the homogenized specimen than in the non-homogenized one. The most remarkable softening of the tensile properties was observed in the H-charged and homogenized specimen at a strain rate of $2 \times 10^{-3} / \mathrm{s}$, resulting in the degradation of both strength and ductility.

Both macro- and micro-hardness measurements using Rockwell and Vickers hardness testers, respectively, showed the consistent trend of $\mathrm{H}$-induced softening. In particular, the hardness in the central region of the H-charged and homogenized specimen was much lower than that of the uncharged but homogenized specimen. The SEM examination of the fracture surfaces showed that only the H-charged and homogenized sample exhibited a wide range of dimple sizes and a slightly brittle and transgranular appearance, while other samples showed mainly typical ductile dimples in the central regions of the fractured tensile specimens.

\section{Acknowledgements}

This study was carried out under the Nuclear R\&D program supported by Ministry of Knowledge Economy in Republic of Korea. This work was also supported in part by the Priority Research Centers Program through the National Research Foundation of Korea (NRF) funded by the Ministry of Education, Science and Technology (2009-0093814). HC also acknowledges partial support from the research program 2010 of Kookmin University in the Republic of Korea.

\section{REFERENCES}

1) R. A. Zidan, S. Takara, A. G. Hee and C. M. Jensen: J. Alloy. Compd. 285 (1999) 119-122.

2) C. Schuh and D. C. Dunand: Acta Mater. 49 (2001) 3387-3400.

3) H. Choe, C. A. Schuh and D. C. Dunand: J. Appl. Phys. 103 (2008) 103518(1-9).

4) E. Hong, D. C. Dunand and H. Choe: Int. J. Hydrogen Energy 35 (2010) 
$5708-5713$.

5) J. H. Kim, M. H. Lee, B. K. Choi and Y. H. Jeong: J. Alloy. Compd. 431 (2007) 155-161.

6) D. Khatamian and V. C. Ling: J. Alloy. Compd. 253-254 (1997) 162 166.

7) P. Sofronis and I. M. Robertson: Proc. 2nd Int. Symp. on Hydrogen in Matter, ed. by G. R. Myneni and B. Hjörvarsson, (Uppsala, Sweden, 2005) pp. 64-70.

8) X. Wu, Y. Katada, I. S. Kim and S. G. Lee: Metall. Mater. Trans. A 35 (2004) $1477-1486$.

9) R. A. Siddiqui and H. A. Abdullah: J. Mater. Proc. Tech. 170 (2005) 430-435.

10) X. Q. Wu and I. S. Kim: Mater. Sci. Eng. A 348 (2003) 309-318.

11) A. M. Brass and J. Chêne: Corros. Sci. 48 (2006) 3222-3242.

12) H. Cho, B. K. Kim, I. S. Kim and C. Jang: Mater. Sci. Eng. A 476 (2008) 248-256.

13) D. W. Kim: Ph.D. thesis, (KAIST, Daejeon, Republic of Korea, 1998) pp. $1-110$.

14) W. Kim, S. Yoon, W. Ryu and C. Lee: J. Kor. Inst. Met. Mater. 46 (2008) 118-124.

15) I. Lee: J. Kor. Inst. Met. Mater. 46 (2008) 357-362.

16) C. S. Marchi, B. P. Somerday, X. Tang and G. H. Schiroky: Int. J. Hydrogen Energy 33 (2008) 889-904.

17) T. Matsuo, J. Yamabe, S. Matsuoka and Y. Murakami: Proc. 2008 Int. Hydrogen Conf., ed. by B. Somerday, P. Sofronis and R. Jones, (Wyoming, USA, 2008) pp. 105-112.

18) D. P. Abraham and C. J. Altstetter: Metall. Mater. Trans. A 26 (1995) 2849-2858.

19) D. P. Abraham and C. J. Altstetter: Metall. Mater. Trans. A 26 (1995) 2859-2871.

20) G. V. Karpenko, N. Y. Yarmchenko and M. M. Shved: Mater. Sci. 7 (1971) 304-306.

21) E. Herms, J. M. Olive and M. Puiggali: Mater. Sci. Eng. A 272 (1999) 279-283.

22) C. Pan, Y. J. Su, W. Y. Chu, Z. B. Li, D. T. Liang and L. J. Qiao: Corros. Sci. 44 (2002) 1983-1993.
23) T. Kanezaki, C. Narazaki, Y. Mine, S. Matsuoka and Y. Murakami: Int. J. Hydrogen Energy 33 (2008) 2604-2619.

24) T. Tabata and H. K. Birnbaum: Scr. Metall. 18 (1984) 231-236.

25) G. R. Caskey, A. H. Dexter, M. L. Holzworth, M. R. Louthan and R. G. Derrick: Corros. 32 (1976) 370-374.

26) Y. S. Kim: Met. Mater. Int. 11 (2005) 29-38.

27) Annual Book of ASTM Standards, vol. 03.01 (E-8), Standard Test Methods for Tension Testing of Metallic Materials, (ASM International, Philadelphia, 1994) pp. 60-81.

28) W. F. Smith: Structure and Properties of Engineering Alloys, (McGraw-Hill, New York, 1993) pp. 312-318.

29) R. W. Hertzberg: Deformation and Fracture Mechanics of Engineering Materials, (Wiley, New York, 1996) pp. 49-51.

30) C. S. Marchi, T. Michler, K. A. Nibur and B. P. Somerday: Int. J. Hydrogen Energy 35 (2010) 9736-9745.

31) S. Fukuyama et al.: J. Japan Inst. Metals 68 (2004) 62-65.

32) S. G. Hong and S. B. Lee: Int. J. Fatigue 26 (2004) 899-910.

33) Y. Murakami, T. Kanezaki and Y. Mine: Metall. Mater. Trans. A 41 (2010) 2548-2562.

34) I. S. Kim and S. S. Kang: Int. J. Press. Vessels Pip. 62 (1995) 123-129.

35) T. Michler and J. Naumann: Int. J. Hydrogen Energy 35 (2010) 14851492.

36) K. A. Nibur, B. P. Somerday, D. K. Balch and C. S. Marchi: Acta Mater. 57 (2009) 3795-3809.

37) K. Oguri, S. Takaki and H. Kimura: Mater. Sci. Eng. 53 (1982) 223232.

38) T. Boniszewski and G. C. Smith: Acta Metall. 11 (1963) 165-178.

39) J. W. Watson, Y. Z. Shen and M. Meshii: Metall. Trans. A 19 (1982) 2299-2304.

40) A. J. West and M. R. Louthan, Jr.: Metall. Trans. A 13 (1982) 20492058.

41) G. R. Caskey, Jr.: Scr. Metall. 15 (1981) 1183-1186.

42) H. K. Birnbaum and P. Sofronis: Mater. Sci. Eng. A 176 (1994) 191202.

43) P. Rozenak, I. M. Robertson and H. K. Birnbaum: Acta Metall. Mater. 38 (1990) 2031-2040. 